\title{
The Impact of Megaproject Stakeholders' Psychological Ownership on Cooperative Innovation Performance: Territorial Behavior and Social Loafing as Mediator
}

\author{
Zhen Chen \\ School of Urban Economics and Management, Beijing University of Civil Engineering and Architecture, Beijing 100044, China \\ Correspondence should be addressed to Zhen Chen; cz0021@126.com
}

Received 28 February 2021; Revised 4 December 2021; Accepted 22 December 2021; Published 7 February 2022

Academic Editor: Junhui Zhang

Copyright ( 2022 Zhen Chen. This is an open access article distributed under the Creative Commons Attribution License, which permits unrestricted use, distribution, and reproduction in any medium, provided the original work is properly cited.

\begin{abstract}
Megaprojects encounter numerous innovation challenges as well as cross-organization cooperation demands. The paper aims to clarify the relationship between stakeholders' psychological ownership and cooperative innovation performance. It proposes modelling the behaviors' mediator process and how and why the megaproject stakeholders' psychological ownership impacts their cooperative innovation performance. The research aims to expand the domain of psychological ownership by temporary crossorganization aspects and reveal behavioral influence mediation mechanism. This paper opted for an empirical study adapting the SEM approach. Tools such as pre-survey and documentary analysis are applied to design the questionnaire scale. This paper acquired 237 valid questionnaires from seven megaprojects to validate the impact of stakeholders' psychological ownership on cooperative innovation performance. This paper finds that the following: (1) the psychological ownership of megaproject stakeholders has a negative impact on cooperative innovation performance, which is realized through the dual mediators of territorial behavior and social loafing; (2) psychological ownership has a positive effect on both territorial behavior and social loafing, while territorial behavior and social loafing have a negative effect on cooperative innovation performance. This paper reveals that psychological ownership's negative influence mechanism on cooperative innovation performance, in temporary cross-organization, further provides support for improving cooperative innovation performance.
\end{abstract}

\section{Introduction and Background}

Megaprojects are uncertain, complex, and politically sensitive projects that cost more than US\$ 1 billion and involve numerous stakeholders' lives and work, which are usually operated by the project department entrusted by the government $[1,2]$. The scale of megaprojects determines that there are a large number of unprecedented innovations in the construction of megaprojects, such as design innovations under ultradesign specifications, technology innovations for large-scale construction, and multistakeholder multicultural collaborative innovations. Furthermore, each innovation point of megaprojects is always a specific multidirectional connection node in the megaproject's system network. As the change of a point often affects the stability of the entire system, the realization of each innovation requires the joint action of multiple connections [3]. Therefore, most of the megaproject's innovations are multistakeholder cooperative innovation.

Studies of human territoriality have long suggested its potential significant effect on the performance and well being of organizations and their members [4]. However, in order to protect their interests, each stakeholder of megaprojects is always inclined to show territorial behavior to himself [5]. It is because that the interests of the vast majority of stakeholders are not completely consistent with the realization of the project value, and the interests of stakeholders are often antagonistic. Meanwhile, due to the cooperative nature of multistakeholders in megaproject's collaborative innovation and contribution commonality, the 
stakeholders often adopt social loafing strategy [6]. These behaviors have hindered various stakeholders' cooperation and produced noncooperation behaviors, cooperative but inaction behaviors, and cooperative behaviors that are only beneficial to themselves, which reduce the outcome and performance of cooperative innovation.

Therefore, based on the social impact theory, expectation theory, and social exchange theory [7], this paper considers stakeholders' psychological ownership, territorial behavior, social loafing, and cooperative innovation performance in the same research framework in the context of megaprojects. Through literature retrieval and theoretical analysis, the research hypothesis is put forward and the conceptual model of this study is constructed. Then, questionnaires designed for stakeholders of seven megaprojects were conducted to investigate the impact of megaproject stakeholders' psychological ownership on cooperative innovation performance. This paper is expected to construct a systematic theoretical framework in terms of reviewing systematically and summarizing the impact mechanism of stakeholders' psychological ownership on cooperative innovation performance. Also, exploring the impact of stakeholders' psychological ownership on social loafing is beneficial for revealing the causes of stakeholders' social loafing at a cooperation level.

\section{Literature Review and Theoretical Basis}

2.1. Concept Definition and Connotation. Psychological ownership is a psychological state, which refers to feeling of possessiveness and attachment toward an object (material or immaterial) [4]. Psychological ownership does not mean really owning an object. It just means a feeling of psychological identity of an object (material or immaterial). The core of psychological ownership is the feeling of possession and of being psychologically tied to an object [8]. Employee ownership can be divided into formal and psychological ownership. Compared with formal ownership, psychological ownership is regarded as virtual ownership. However, the formal ownership of employees does not directly affect their attitudes, motivation, behaviors, and job performance, but through psychological ownership [9].

Territorial behavior is derived from zoology, indicating that animals recognize and protect their own territories, spouses, etc. Management scholars introduce territorial behavior into the field of management in order to characterize a type of human behavior. Territoriality is defined as an individual's behavioral expression of his or her feelings of ownership toward a physical or social object. Territorial behaviors refer to actions or behaviors that often emanate from psychological ownership for the purposes of constructing, communicating, maintaining, and restoring territories around those objects in the organization toward which one feels proprietary attachment [4]. Territorial behavior becomes a kind of selfless behavior to protect one's own objects from others [10]. Territorial behavior is divided into marking behavior and defensive behavior. Territory marking behavior is divided into identity-oriented marking and control-oriented marking. Identity oriented is derived from the subject's self-needs in terms of personality and uniqueness. It is the process of constructing individual identity and defining the difference between individuals and others. Control oriented is used to control related objects. Using the right prevents others from entering, using, and infringing upon their own territory. Defensive behavior includes pre-defense and reactive methods. Pre-defense is the defense before the invasion occurs, and reactive defense is the defense that passively resists the invasion and repairs the damaged territory after the subject is violated [11]. Previous territorial behavior studies focus on several aspects : employee creative [12-14], knowledge hiding [15], knowledge sharing [16, 17], and turnover intention [19]. The main views are as follows: territorial behavior has significant positive to knowledge hiding and turnover intention; then, it has significant negative influence on employee's creative. However, it has a significant positive influence on the team's creative because territorial behavior induces team cohesion [4]. There is a rare study on territorial behavior in cross-organization teams.

Social loafing is a motivational construct [20], a common social phenomenon in which the performance of individuals working together is significantly lower than that of individuals working independently, resulting in a waste of organizational manpower [21]. Based on meta-analysis, social loafing is a phenomenon in which individual efforts in the collective are less than those done independently [22]. Social loafing is a common social behavior in which individual behaviors caused performance of individuals working in a group become significantly lower than that of individuals working alone, resulting in a waste of organizational productivity and success [23-25]. Social loafing is considered to be a serious problem that affects the quality of team decision-making and the quality and quantity of team creativity [26]. Existing research studies identified that social loafing originates from the combined effect of external factors (task visibility, contribution perception, and fairness) and internal factors (task significance, task importance, organizational commitment, and turnover intention) $[23,27]$. So, social loafing can be determined by individual's internal psychological factors.

Previous study on social loafing driving factors focus on mission, leadership, team characters, personality characteristics, personality behaviors, and external resource.

Increase in task interdependence and decrease in task visibility are associated with greater occurrence of social loafing $[28,29]$. From leadership style, ethical leadership and supportive leadership are negatively associated with social loafing $[30,31]$.

From team characters, social loafing behavior is most common for team members who are part of a team with strong fault lines, who belonged to the larger subgroup in their team, and who exhibit low levels of social competence [21]. Perceived organizational politics is positively associated with social loafing [32]. Team cohesion, team norms, and team feedback with guided reflexivity are negatively associated with social loafing $[33,34]$. Team size is positively associated with social loafing and mediated the effect of diffusion of responsibility, attribution of blame, and dehumanization [29, 35]. 
Social loafing is negative associated with organizational characters in the team. First, perceived social loafing is negatively associated with team cohesion, team satisfaction, and result satisfaction [34]. Social loafing decreases team personal willingness to help and personal effect $[36,37]$. Second, perceived social loafing is negatively associated with team learning performance and mediated the effect of team affective tone [38].

To solve this problem, the measures are as follows. First, combining individual performance and team performance decreases social loafing effectively. When individual performance is not posted, employees working in a team perform worse than when working alone (i.e., social loafing) [39]. Nominal group technique (NGT, a systematic approach to soliciting individual inputs into group project design and planning) and preference for group work decreases social loafing [40, 41]. Second, leaning management is used for decreasing social loafing [42]. Third , strategic innovation decreases social loafing behaviors effectively [25].

From personal characters, girls have slightly higher social loafing than boys [43]. In the "Big Five" model, extraversion and neuroticism are positively associated with social loafing [44]. Moral meaningfulness and mindfulness decreases social loafing attitude and intention [45]. Work ethic and professional respect decreases social loafing $[28,46]$. Low mental toughness induces employee social loafing [40]. Effects of intrinsic and extrinsic motivation on social loafing are more complex. Enjoyment in helping exhibits negative relationship with social loafing. Reputation and reciprocity exhibits positive relationship with social loafing [47].

From personal characters, organizational citizenship behavior decreases social loafing [48]. Social loafing can be effectively diminished by raising interactional justice and benevolence-based trust [7]. Co-worker support, job insecurity, and turnover intention are positively associated with social loafing $[49,50]$.

From external resource, virtuality office work is positively associated with social loafing and moderated the effect of family responsibility, with high level of family responsibility which induces a high level of social loafing. Cohesion and obligation are negatively associated with social loafing [51]. Work ostracism decreases employee social loafing and moderated the effect of work seniority, with longer work seniority, and decreases social loafing more [52].

Although a lot of study on the antecedents of social loafing demonstrate driving factors from mission, leadership, team characters, personality characteristics, personality behaviors, external resource, and rare study on territorial behavior.

Cooperative innovation performance refers to the innovation results produced by two or more stakeholders sharing complementary resources among them for common interests on the basis of cooperation [53]. From enterprises' cooperative innovation performance, it is composed of understanding and absorbing external knowledge, integrating external knowledge with existing knowledge and promoting exploratory innovation [13]. Empirical research has indeed shown that "to cooperate" behaviors, just like moral behavior, affect cooperative innovation performance $[54,55]$. Previous cooperative innovation study exhibits cooperation which is positively associated with innovation, so cooperation ties innovation closely [56]. A previous study on cooperation innovation performance driving factors focuses on mission, leadership, organization characters, organization structure, and external resource. Mission oriented exhibits organizational members have mission heterogeneity and culture heterogeneity. It is hard to acquire a high level of cooperative innovation performance caused by these heterogeneities $[13,57,58]$. Environmental dynamism is significantly positively associated with cooperation innovation performance [59]. From leadership style, transactional leadership and transformational leadership are benefit to cooperative innovation performance $[60,61]$. Organization characters driving scholars exhibit learning behaviors (exploration learning and exploitation learning) which are positively associated with cooperative innovation performance $[13,57,58]$. Knowledge integration has positive effect to cooperative team performance when need for cognition is high or when resource interdependence is high [62]. Psychological distance is negative associated with cooperative innovation performance [63], but trust, commitment, and support are positively associated with it $[60,61,64]$. Alliance portfolio management capability is associated with cooperative innovation performance mediating the positive effect of knowledge power and relational learning [65]. From evidence from Chinese firms we know that internal cooperation network has the most significant and positive impact on their cooperative innovation effect, and firm government cooperation does not demonstrate any significant impact on the innovation performance of firms [66]. There are significantly positive relationships between firms' internal capabilities, government policies, collaboration mechanisms and social networks, and collaborative innovation effect among firms [67]. External resourcedriving scholars demonstrate specific investments which are beneficial to cooperative innovation performance mediating the positive effect of relational trust $[53,68,69]$. Although previous studies explain the antecedents from mission, leadership, organization characters, organization structure, and external resource. There is a rare study on psychological ownership to explain cooperative innovation performance and the driving way. Perceived ownership influences the development and then influence cooperation with other parts to complete the megaproject. It is necessary to verify the driving mechanism from psychological ownership to cooperative innovation performance.

It is proved that cooperative $R \& D$ contributes to firm performance [70]. Levine defined the calculation formula of cooperative innovation performance [71]. Evidence from Chinese companies' experience showed that cooperative innovation performance has a significant positive influence on the innovation performance of enterprises [66]. Therefore, cooperative innovation performance is proposed as an index to evaluate the degree of cooperative innovation [68].

Megaproject stakeholders' cooperative innovation performance depends on the innovation interaction behaviors 
among all megaproject stakeholder (e.g., owners, contractors, subcontractors, supervisor, and consultor), concluding intraorganizational and interorganizational innovation interaction behaviors. Different from the definition of megaproject cooperative innovation, it focuses on cooperative behaviors among two or multiple stakeholders, which ensure the successful realization of megaproject success [72]. Different from the definition of firm cooperative innovation, it focuses on intraorganizational and interorganizational innovation interaction behaviors, which are hierarchy (e.g., owners and contractor relationship) and equal partner (e.g., subcontractor and subcontractor relationship) relationship between different stakeholders, not pure equal partner relationship.

2.2. The Impact of Stakeholders' Psychological Ownership on Cooperative Innovation Performance. Collaborative innovation requires all participating stakeholders to jointly apply their respective advantages to solve problems together. Psychological ownership requires distinguishing between what one owns and what others have in the organization. It means that one defends others' infringement naturally if he/ she does not think they are team partners. Collaboration means helping and sharing what one has and means reducing the boundaries and defensive behaviors between people [73]. It is hard to get cooperative innovation performance because cooperative innovation behavior occurs rarely in this organizational field.

Although there is no direct evidence to show the relationship between psychological ownership and cooperative innovation performance, but indirect research may support Hypothesis 1. From the perspective of knowledge management, stakeholders' psychological knowledge ownership has a negative influence on knowledge sharing among stakeholders [17, 74]. Knowledge sharing among stakeholders can improve the efficiency of stakeholder cooperation [75]. Given these findings, it suggests that psychological ownership inhibits the cooperation among stakeholders to some extent. Thus, the following hypothesis is proposed.

Hypothesis 1 (H1). The megaproject stakeholders' psychological ownership has a negative impact on the cooperative innovation performance of stakeholders.

\subsection{The Impact of Stakeholders' Psychological Ownership on} Territorial Behaviors. Psychological ownership comprised self-identity and sense of belongingness [76]. Psychological ownership is rooted in self-identity, dividing the organizational objects from one's own to others and providing physical and psychological security and performance to one's own objects [4]. Psychological ownership establishes the individual's sense of belongingness, so the individual makes organizational commitment to the individual's own territory of the organization. So, social loafing may originate from psychological ownership.

When introducing territorial behavior from biological domain to the organizational domain, Brown has noticed that psychological ownership was an antecedent of territorial behavior and verified the positive impact of psychological ownership on territorial behavior $[4,73]$. The psychological ownership of the target is realized through defending behavior in territorial behavior [73]. Liu et al. [77] believed that when an object can become an extension of "self," it will be given psychological ownership by the individual, and the individual will also show territorial behavior to this object [77]. Therefore, Hypothesis 2 is proposed.

Hypothesis 2 (H2). The megaproject stakeholders' psychological ownership has a positive impact on the territorial behaviors of stakeholders.

2.4. The Impact of Territorial Behaviors on Cooperative Innovation Performance. Taking into account the insecurity and innovation risks of work, stakeholder members adopt defensive actions in territorial behavior to prevent others from invading their innovation fields, resulting in low collaborative innovation performance [18]. With low individual innovation performance and low cooperation rate in project, it is hard to get more cooperative innovation activities to increase performance $[56,78,79]$.

Liu et al. [80] have demonstrated that both internal territorial behavior and external territorial behavior have a negative effect on team performance, and the higher the requirement of task interdependence, the stronger the negative effect of internal territorial behavior on team performance [77]. Furthermore, in terms of knowledge management, Liu et al. [80] pointed out that internal territorial behavior negatively affects knowledge sharing through destroying the team identity of individuals and the relationship among team members [80]. However, it is proved that knowledge sharing is beneficial to improve cooperation efficiency [75]. Therefore, Hypothesis 3 is presented.

Hypothesis 3 (H3). The megaproject stakeholders' territorial behaviors have a negative impact on cooperative innovation performance of stakeholders.

\subsection{The Impact of Stakeholders' Psychological Ownership on} Social Loafing. Psychological ownership is a feeling of possessiveness and attachment to organizational objects. Organizational members with a sense of psychological ownership work more positive over their own jobs [73]. On the one hand, organizational members take less care on cooperative behaviors with a sense of no impact on individual's possessiveness and attachment. It shows that organizational members take more social loafing behaviors on stakeholder's cooperation to defend others infringing their own benefits. On the other hand, based on exclusive property protection, organizational members take social loafing to defend others from their own organization, which formed knowledge hiding behavior and other negative behaviors [74, 81].

Existing studies show that engineering designers' knowledge-based psychological ownership causes knowledge contribution loafing directly [30]. The reason could be 
that the increase of stakeholders' psychological ownership may reduce their external connections and thus reduce coworker support; however, the reduction of co-worker support will lead to the increase of social loafing [49]. Therefore, Hypothesis 4 is developed.

Hypothesis 4 (H4). The megaproject stakeholders' psychological ownership has a positive impact on social loafing of stakeholders.

\subsection{The Impact of Social Loafing on Cooperative Innovation} Performance. Studies have shown that, on the one hand, social inertia can negatively regulate team member exchanges and organizational citizenship behavior [82], while organizational citizenship behavior can positively affect innovation performance [83] and organizational citizenship behavior also has a positive effect on cooperation effectiveness [84]. On the other hand, knowledge transfer has a significant positive effect on cooperative innovation performance [68], while social loafing has a significant negative influence on knowledge transfer [85]. Therefore, social loafing may have negative effects on organizational citizenship behavior and knowledge transfer, while organizational citizenship behavior and knowledge transfer may have positive effects on innovation performance and cooperative effectiveness. According to this, Hypothesis 5 is proposed.

Hypothesis 5 (H5). The megaproject stakeholders' social loafing has a negative impact on cooperative innovation performance of stakeholders.

According to the hypotheses above, the conceptual model of this study was proposed (see Figure 1).

\section{Methodology}

SEM is a statistical modelling technique which is employed in the field of social science which verify the relationship between different latent variables [86-88]. Classically, since stakeholders' psychological ownership, territorial behavior, social loafing, and cooperative innovation performance are all subjective construct, the present employs questionnaire surveys to obtain variable data and structural equation model to capture the maximum explanation from the hypothesized relationship [86-88].

3.1. Research Sample. This paper selects seven Chinese megaprojects as research samples for two reasons. First, China's major engineering construction organizations need to obtain larger-scale and higher-quality construction products through cooperative innovation to meet the needs of the owners. It is valuable to understand how people in major engineering construction organizations use psychological ownership to change their cooperative innovation performance in the Chinese context. Secondly, limited by the major engineering practice cases available to the author, sufficient samples can be obtained by collecting data in China.

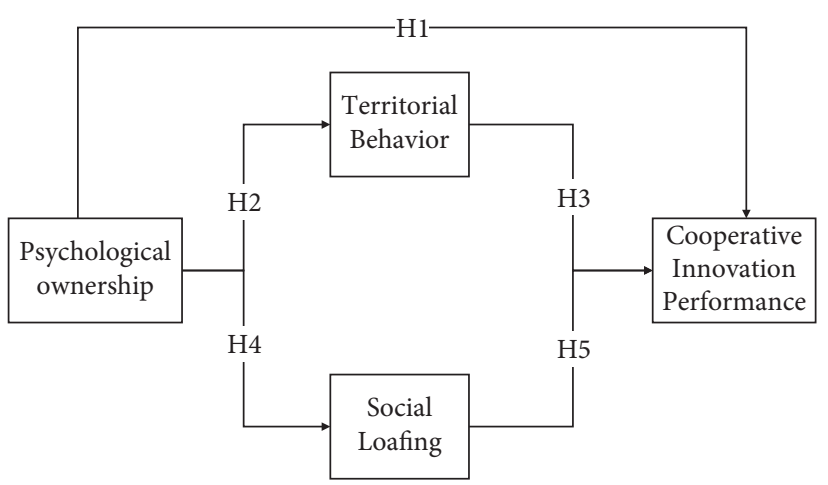

FIGURE 1: concept model of impact of megaproject stakeholders' psychological ownership on cooperative innovation performance.

The investment in these seven major Chinese projects each exceeded RMB 1 billion and affected the daily life of hundreds of thousands of residents, such as their travel and power supply. All questionnaire survey objects include project owners, designers, general contractors, subcontractors, material suppliers, and supervisors. The investigation steps are as follows. First, the author adds the WeChat accounts of all visitors and confirms their identity information in the project. Secondly, the author sends the electronic version of the questionnaire to their WeChat account. Third, the author separately called all the interviewees to confirm that they had received the questionnaire through WeChat, and then, the author explained to them the difficult questions they encountered to confirm whether they really understood the meaning of all the items. Finally, the author told all the interviewees the final deadline for submitting the questionnaire. At the deadline, the author would call all those who had not submitted the questionnaire to remind them to send back all the questionnaires as soon as possible.

The empirical research involves two major projects in China. This paper uses pre-survey and literature analysis to obtain the questionnaire scale. First, compare the different constructs in the items through literature analysis, paying special attention to previous similar articles and the context of major engineering organizations. Second, investigate the stakeholder members of two major projects for pre-survey. Analyze the results and adjust the description of the questionnaire items, adding or deleting part of the content based on the major engineering practice scenarios. Then, the final questionnaire is formed.

The timeline when this survey (including pre-survey) was completed is from July to September 2020. During presurvey period, this paper investigated 63 project managers from two megaprojects (Beijing Medium and Low-Speed Maglev Traffic Demonstration Line (S1) and Beijing's new airport terminal area). After eliminating invalid questionnaires, a total of 60 valid questionnaires were collected. This paper applies the definition of megaprojects proposed by Flyvbjerg: firstly, the total investment of Beijing S1 line and Beijing new airport terminal is 6.4 billion and 80 billion respectively; secondly, the S1 line improves the travel of citizens in Mentougou District and Shijingshan District, and 
the new airport facilitates the movement of Beijing citizens; thirdly, S1 line project there exists technical complexity and management complexity of the magnetic suspension construction, and the new airport has the complexity of largespan steel structure construction technology and management. Therefore, these two projects meet the definition of a megaproject because of their significant impact on hundreds of thousands of people's lives, construction and management complexity, and billions of dollars in investment.

Based on adjusting measurement items after pre-survey, a formal survey was carried out from October to December 2020. This paper selected 247 project managers as respondents, who come from seven megaprojects located in Beijing, Shanghai, Yulin Shaanxi, and Xiongan New Area. These projects meet the requirements of the aforementioned megaprojects. After eliminating the questionnaires with too many blanks, too neutral, or too obvious response tendencies, 237 questionnaires were considered to be valid (95.95\% recovery rate). The investigated stakeholders mainly come from owners (13.50\%), designers (15.19\%), general contractor $(25.74 \%)$, material suppliers $(8.86 \%)$, subcontractor (22.78\%), and supervisor (13.92\%). Among them, males accounted for $60.34 \%$ and females accounted for $39.66 \%$. Stakeholders' age under 30 years (30.88\%), 31-40 years $(44.73 \%), 41-50$ years $(12.24 \%), 51-60$ years $(11.81 \%)$, and over 61 years $(0.84 \%)$. In addition, in terms of working experience in participating in corresponding projects, 27.43 percent of respondents have less than one year of experience, 58.65 percent of them have one to three years of experience, and 13.92 percent of them have more than 3 years of experience. The questionnaire was made online and distributed on the website Wenjuanxing through targeted contact with project stakeholders. The questionnaire would be sent back after they completed the questionnaire.

3.2. Measurements'Scale and Its Improvement. It is necessary to choose approximate scales to measure these latent variables. However, not all scale items are proper for this organizational environment of megaprojects. Some items need to be improved to adapt these scales to this research. In order to confirm the validity of these scales, this article uses research samples to test the reliability of the questionnaire through Cronbach's $\alpha$ value [89].

3.2.1. Stakeholders' Psychological Ownership. Although psychological ownership scale towards enterprises is normal $[4,77,80]$, psychological ownership scales towards temporary organization like project is rare. Combining with psychological ownership scales towards enterprises, based on Megaproject's Psychological Ownership Scale developed by $\mathrm{He}$ et al. [90], this paper conducted a small-sample test and then adjust, restate, and interpret the measurement items (7 items). Compared to Brown's scale, first, it fits construction site engineers to reply from the engineering context, with reduction items towards the workspace to reply $[4,11]$. Because megaproject workspace instability, all employees need to fit for changing workspace complied with project schedule [91]. Second, Brown's scale does not fit for
Chinese context [77]. Compared to Liu's scale, He's scale takes more focus on employee's perceived of belongingness to the project organization, which is a cross enterprises' temporary organization. Cronbach's $\alpha$ value of this scale was 0.77 .

3.2.2. Territorial Behaviors. Although Brown [11], Liu et al. [80], and Wang et al. [6] developed the territorial behaviors' scale, none of them match the megaproject organizational environment. Because the scale of team territory behavior constructed by Liu et al. [77] was designed for infrastructure operation companies that have a certain similarity with megaprojects situation and Liu's scale developed by Chinese interviewees' data, this scale was adopted in this paper [80]. Brown's and Wang's scales all focus on enterprise territorial behaviors, which does not implicate organizational temporary. The territorial behaviors should combine the crossenterprise teams into a temporary organization, resist myopic behaviors, and protect temporary organizations. Combined with the situation of megaprojects' stakeholders, a small-sample test was conducted and the items were reinterpreted (8 items). Internal Territorial Behavior and External Territory Behavior scales consisted of 4 items each. Cronbach's $\alpha$ value of this scale was 0.81 .

3.2.3. Social Loafing. Most scholars use George's scale [23] to measure social loafing; the reason is as follows. First, George published this scale on Academy of Management Journal, the top journal of management, which carries academic authority. Second, George published this scale in 1992; previous empirical research verified this scale's validity repeatedly. Third, this scale could be applied on salesperson. Most of enterprises need the scale to prevent salespersons' social loafing. However, project management does not need salesperson because construction produces are all personalized customization and the contractors are bid on this project before construction. So, George's scale is not fit for this research. This variable was measured by Social Loafing Scale developed by Kidwell et al. because it was a developed scale for the organization concluding the temporary organization [92]. According to interviewing with project managers, the item "I am often late" was deleted due to strict implementation on fingerprint or iris recognition time clock. None employee in megaproject is employed with the condition of "I am often late." In context of megaprojects' stakeholders, this paper performed a small-sample test and reinterpreted items (6 items). Cronbach's $\alpha$ value of this scale was 0.79 .

3.2.4. Cooperative Innovation Performance. Although there are numerous scale items of cooperative innovation performance, it is hard to seek proper items based on project stakeholders' perspective to measure cooperation innovation performance for this research. The megaproject stakeholders could be supposed to alliance portfolio to achieve megaproject's objectives [93]. Therefore, based on the scales of Yin and Shao that investigated the alliance 
portfolio management capability [65], this paper conducted a small-sample test, combined with megaproject stakeholders' situation, and then redescribed the items (4 items). Yin's scale maintains using $\mathrm{R} \& \mathrm{D}$ work to rise sales volume. However, megaprojects' construction sales volume is definite. So, this study items change "sales volume" to "higher outcomes." Yin's scale maintains "clients" in the items because they do not know the specific client, but this study items changes "clients" to "owners." Cronbach's $\alpha$ of this scale was 0.82 .

The measurement scale of this study is shown in Appendix. The Likert 5-point scale is used to measure all the questions in the questionnaire. The answers to the above questions are divided into 5 grades according to the attitude of approval, from 1 very disagree to 5 very agree.

3.3. Analysis of Data. SPSS (22.0) and LISREL (8.80) software were utilized for the analysis of data. Propositions were analyzed using SEM. This technique is robust to explain the hypothesized relationships between multiple dependent variables and perform the analysis simultaneously [94]. Due to robustness and efficiency, SEM provides enough reliability, validity, accurate, and meaningful outcomes [95]. Compared with PLS-SEM, because the data comply with the assumptions of linearity and normality (see Table 1) and the model is not complex, it does not need to employ the PLSSEM to analysis this model $[96,97]$. Furthermore, the SEM verifies a variety of hypotheses instantly incorporating mean structures estimations which are very difficult to be carried out in other techniques [94].

\section{Result}

4.1. Descriptive Statistics and Correlation Analysis. This study uses the Statistical Product and Service Solutions (SPSS) (23.0) software to analyze the reliability test of each construct. The mean, standard deviation, correlation coefficient, and internal consistency of all constructs are shown in Table 2, and the skewness, skewness standard error, kurtosis, and kurtosis standard error are shown in Table 1. Cronbach's $\alpha$ value of internal consistency reliability was greater than 0.7 , indicating that psychological ownership, territorial behavior, social inertia, and cooperative innovation performance can meet the general requirements of constructing structural equations, and the significance has passed the test. All skewness/skewness standard error is less than 1.96, and all kurtosis/kurtosis standard error is less than 1.96. It proves that the construct variables are all meeting normal distribution requirements.

4.2. Reliability Analysis. First, Cronbach's $\alpha$ coefficient and combined reliability $\mathrm{CR}$ are used for reliability test. The results are shown in Table 1. Cronbach's $\alpha$ of all constructs are greater than 0.7 , indicating that the sample data has good reliability. The AVE values were all greater than 0.5 , which passed the test of significance. The results of reliability and validity test are shown in Table 3.
4.3. Hypothesis Testing. In order to verify these hypotheses, the structural equation model (SEM) was used for statistical analysis of the collected data in this paper [98]. In recent years, there has been a lot of empirical research articles using SEM to analyze Likert Scale data in construction management [99]. All conditions satisfied SEM, especially concluding multivariate normality and enough scale sample $[98,100]$. In this research, it used LISREL $(8.80)$ to examine practical model and hypotheses.

Using LISREL (8.80) software, confirmatory factor analysis (CFA) with maximum likelihood estimation was applied to verify the validity of questionnaire results. Table 4 shows the results of this structural equation model. Figure 2 shows the best model results.

To test the above hypothesis, this paper constructed five models. Among them, model 1 refers to the impact of psychological ownership on cooperative innovation performance, which was a two-factor single-path model and was used to verify the direct effect in Hypothesis 1. Model 2 represents the moderating influence of territorial behavior on the relationship between psychological ownership on cooperative innovation performance, which was a threefactor two-path model and aimed to verify Hypotheses 1-3. Model 3 shows the mediating effect of internal territorial behavior and external territory behavior on the relationship between psychological ownership on cooperative innovation performance, which was a four-factor two-path model and aimed to verify Hypotheses 1-3. Model 4 refers to the moderating impact of social loafing on the relationship between psychological ownership on cooperative innovation performance, which was a three-factor two-path model and was used to verify Hypotheses 1, 4, and 5. Model 5 describes the mediating effect of territorial behavior and social loafing on the relationship between psychological ownership on cooperative innovation performance, which was a five-factor three-path model and was used to verify Hypotheses 1-5. In addition to the normed fit index (NFI), root mean square (RMR), and root mean square error of approximation (RMSEA) in model 1, other results passed the test.

\section{Discussion}

This study provides evidence to support the first hypotheses, that is, megaproject stakeholders' psychological ownership has a negative impact on the cooperative innovation performance of stakeholders. However, this effect is not strong. Especially, in model 1, the results were not significant, and the fit goodness of model 1 was the worst among the five models, which has a difference with hypotheses 1 proposed in the theoretical part. Therefore, there is not rejected the possibility of other mediators, which needs further evidences on other mediation models.

For the second and third hypotheses, the research verified the hypothesis that the psychological ownership of stakeholders negatively affects the performance of cooperative innovation through the intermediary of territorial behavior. Although stakeholders cooperated with each other, the degree of mutual trust is still low, which leads to frequent territorial behaviors and ultimately damages the 
TABLE 1: Construct kurtosis and skewness.

\begin{tabular}{lcccc}
\hline Construct & Skewness & Skewness standard error & Kurtosis & Kurtosis standard error \\
\hline Psychological ownership & 0.224 & 0.149 & 0.331 & 0.297 \\
Territorial behavior & 0.244 & 0.149 & 0.305 & 0.297 \\
Social loafing & -0.227 & 0.149 & 0.280 & 0.297 \\
Cooperative innovation performance & 0.221 & 0.149 & 0.323 & 0.297 \\
\hline
\end{tabular}

TABLE 2: Descriptive statistics and correlation coefficient of variables.

\begin{tabular}{lccccc}
\hline Construct & Mean & SD & 1 & 2 & 3 \\
\hline Psychological ownership & 3.75 & 0.75 & $(0.77)$ & & \\
Territorial behavior & 3.82 & 0.71 & $0.488^{* *}$ & $(0.81)$ & $(0.79)$ \\
Social loafing & 3.66 & 0.68 & $0.257^{* *}$ & $0.219^{*}$ & $0.292^{* *}$ \\
Cooperative innovation performance & 3.61 & 0.74 & $0.376^{* *}$ & $0.413^{* *}$ & $(0.82)$ \\
\hline
\end{tabular}

Note. SD, standard deviation; ${ }^{*} p<0.05 ;{ }^{* *} p<0.01 ;{ }^{* * *} p<0.001$; (XX), Cronbach's alpha coefficient.

TABLE 3: Results of reliability and validity test.

\begin{tabular}{|c|c|c|c|c|c|}
\hline Construct & Items & Factor loading & $\mathrm{CR}$ & AVE & Cronbach's $\alpha$ \\
\hline \multirow{7}{*}{ Psychological ownership } & 1 & $0.86^{* *}$ & \multirow{7}{*}{0.9279} & \multirow{7}{*}{0.648} & \multirow{7}{*}{0.77} \\
\hline & 2 & $0.84^{* *}$ & & & \\
\hline & 3 & $0.81^{* *}$ & & & \\
\hline & 4 & $0.77^{* *}$ & & & \\
\hline & 5 & $0.79^{* *}$ & & & \\
\hline & 6 & $0.80^{* *}$ & & & \\
\hline & 7 & $0.76^{* *}$ & & & \\
\hline \multirow{8}{*}{ Territorial behavior } & 1 & $0.77^{* *}$ & \multirow{8}{*}{0.9325} & \multirow{8}{*}{0.6338} & \multirow{8}{*}{0.81} \\
\hline & 2 & $0.82^{* *}$ & & & \\
\hline & 3 & $0.86^{* *}$ & & & \\
\hline & 4 & $0.73^{* *}$ & & & \\
\hline & 5 & $0.76^{* *}$ & & & \\
\hline & 6 & $0.81^{* *}$ & & & \\
\hline & 7 & $0.77^{* *}$ & & & \\
\hline & 8 & $0.84^{* *}$ & & & \\
\hline \multirow{6}{*}{ Social loafing } & 1 & $0.84^{* *}$ & \multirow{6}{*}{0.9236} & \multirow{6}{*}{0.6689} & \multirow{6}{*}{0.79} \\
\hline & 2 & $0.83^{* *}$ & & & \\
\hline & 3 & $0.75^{* *}$ & & & \\
\hline & 4 & $0.89^{* *}$ & & & \\
\hline & 5 & $0.81^{* *}$ & & & \\
\hline & 6 & $0.78^{* *}$ & & & \\
\hline \multirow{4}{*}{ Cooperative innovation performance } & 1 & $0.92^{* *}$ & \multirow{4}{*}{0.9011} & \multirow{4}{*}{0.6958} & \multirow{4}{*}{0.82} \\
\hline & 2 & $0.81^{* *}$ & & & \\
\hline & 3 & $0.82^{* *}$ & & & \\
\hline & 4 & $0.78^{* *}$ & & & \\
\hline
\end{tabular}

Note. ${ }^{*} p<0.05 ;{ }^{* *} p<0.01 ;{ }^{* * *} p<0.001$.

TABLE 4: CFA results of measured models.

\begin{tabular}{lcccccrr}
\hline Models & $\Delta \mathrm{X}^{2} / \mathrm{d} f$ & NFI & NNFI & IFI & CFI & RMR & RMSEA \\
\hline Model 1 & 2.97 & 0.89 & 0.90 & 0.90 & 0.91 & 0.041 & 0.082 \\
Model 2 & 2.63 & 0.91 & 0.93 & 0.93 & 0.94 & 0.036 \\
Model 3 & 2.45 & 0.92 & 0.93 & 0.93 & 0.95 & 0.034 \\
Model 4 & 2.66 & 0.91 & 0.92 & 0.93 & 0.94 & 0.037 \\
Model 5 & 2.39 & 0.91 & 0.93 & 0.94 & 0.96 & 0.033 & 0.072 \\
\hline
\end{tabular}

Note. $N=237 ; \Delta \mathrm{X}^{2}$, Chi-square; $\mathrm{d} f$, degrees of freedom; NFI, normed fit index; NNFI, nonnormed fit index; RMR, root mean square; IFI, increase fit index; CFI, comparative fit index; RMR, root mean square; RMSEA, root mean square error of approximation. 


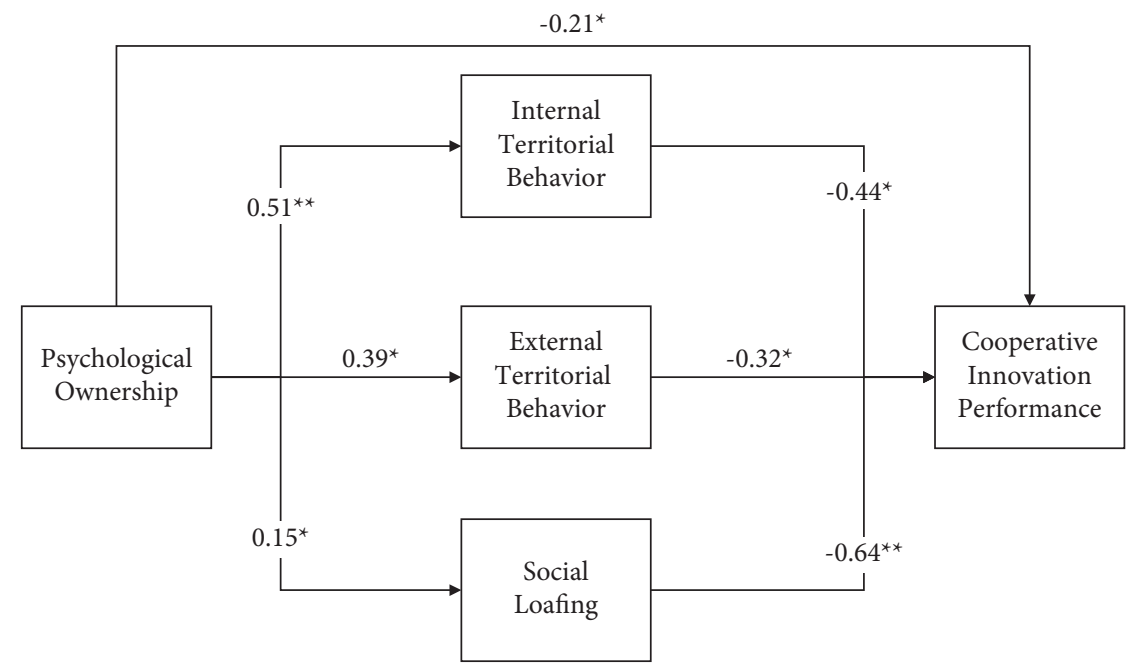

Figure 2: Analysis of the structural model 5. Note: ${ }^{*} P<0.05 ;{ }^{* *} P<0.01 ;{ }^{* * *} P<0.001$.

cooperative innovation performance of the stakeholders [73]. It complies with the studies of Wang et al. [63] that psychological distance has a significant negative influence on cooperative innovation performance [63]. Specifically, the negative impact of external territorial behavior is greater than that of internal territorial behavior, which is different from the conclusions drawn by Liu et al. [77]. One explanation for this divergence could be due to different research objects. External territorial behaviors studies of Liu et al. [80] were designed for individuals from one corporation. In a corporation, different departments' communication relies on mature corporation communication mechanism. This research objects were cross-organizational stakeholders in the project. In the project as temporary organization, it is hard to establish mature communication mechanism because the temporary organizational duration is uncertain and temporary organizations need to go through many different stages; each stage has different one-time missions [77]. Lack of communication caused information asymmetry. Information asymmetry caused the negative impact of external territorial behavior, which is greater than that of internal territorial behavior [42]. Furthermore, different stakeholders originated from different corporation organizations and combined them into one temporary organization. Different corporation organization defending behaviors caused the negative impact of external territorial behavior, which is greater than that of internal territorial behavior [80]. Therefore, in cross-organizational project, employee's external territorial behavior has more correlation with the relationship between psychological ownership and cooperative innovation performance.

The fourth and fifth hypotheses verified the hypothesis that the psychological ownership of stakeholders negatively affects the performance of cooperative innovation through the mediation of social inertia. Although psychological ownership has a positive effect on social inertia, this effect is relatively weak, which is consistent with the research of Sun et al. [30]. This work also proves that social loafing has a significant negative impact on cooperative innovation performance. There is a negative relevance between social loafing and collaborative behaviors [31]. Lack of collaborative behaviors caused low cooperative innovation performance.

\section{Conclusions}

Studies have demonstrated that employees who form territorial consciousness could show significant prosocial behavior towards the territory, while they will show repulsive behavior towards outsiders of the territory $[76,77]$. Similarly, employees who form territorial consciousness will protect their knowledge to prevent them from flowing to others through sharing knowledge, knowledge hiding behaviors, and other negative behaviors [30, 101, 102]. Therefore, based on the context of megaprojects, this study constructed a driving mechanism of stakeholders' psychological ownership on cooperative innovation performance of stakeholders under a cross-organizational context. This study found that both territorial behavior and social loafing negatively moderated the relationship between megaproject stakeholders' psychological ownership and cooperative innovation performance. Specifically, megaproject stakeholders' psychological ownership has not only a direct effect on cooperative innovation performance but also an indirect impact through both territorial behavior and social loafing. This research can be used to design the management mechanism and incentive mechanism of multistakeholder cooperative innovation management of megaprojects. The results have implications for megaproject stakeholders' cooperative innovation management in designing management mechanisms and incentive mechanisms. This study value as follows. First , based on the megaproject innovation context, this study constructs psychological ownership to cooperative innovation performance driving mechanism which is not mentioned in other literature studies. Second, other literature studies discuss territorial behaviors as a kind of prosocial behaviors because employee's identity-oriented 
marking, control-oriented marking, and defending behaviors [4]. The employee can clearly identify the boundary of their organizations and protect their own organizations. This study explores how the territorial behaviors influences cooperative innovation performance in cross-organization complex structure. This study discusses the dark of the territorial behaviors. Unlike in the same organizations, the territorial behaviors display antisocial aspect. The empirical research result maintains the employee identity their boundary to their team of the enterprise. Cross-organization cooperation is hard due to the psychological ownership. Third, psychological ownership is positive to social loafing because of their identity of the boundary of their organization. The employees are indifferent to other organization work, with social loafing behaviors occurring.

Based on the above research, some suggestions for improvement are as follows:

Firstly, performance appraisal system of cooperative innovation should be improved. The root cause of social loafing is that performance is not implemented to individuals [39]. Therefore, even if the task is completed by cooperation, it is very important to reduce the social inertia by marking each person's contribution in the cooperation separately and making it public.

Secondly, megaproject employees' territorial consciousness should be strengthened. Avey et al. [76] concluded that employees who form significant territorial consciousness could show strong prosocial behavior inside the territory, enhance cooperation within the territory, and defend against external shocks [76]. In summary, it is necessary to educate and cultivate the awareness of project territory for megaproject employees. The flattening management should be strengthened and employees of all stakeholders could be invited to participate in project meetings and activities (e.g., annual meetings), focusing on the full participation of the project department as a whole. Also, it is essential to unify the distribution of welfare for all stakeholders within the project department. These suggestions could help the megaproject employees form project territorial awareness and reduce the friction and conflict among stakeholders within the project.

Thirdly, the employee's interest in megaprojects should be developed. Schippers et al. pointed out that, although social loafing exists, when faced with complex tasks, team members' high sense of responsibility and high acceptance of tasks may motivate some interested employees to actively complete the unfinished work. These behaviors could achieve compensation for the team's internal performance and reduce the damage of social loafing [103]. Therefore, this work provides an important means to reduce megaprojects' social loafing by condensing the innovation of tasks and combining repetitive work with innovative work, which will make employees more interested in their work.

Several limitations of this research deserve to be addressed. Firstly, due to the limited data resources and research time, this study only explored seven megaprojects' stakeholders, while there are thousands of full-scale megaprojects in China. Therefore, a considerable number of respondents came from the same project, which may cause one-sided results. Future work will continue to expand the sample size and increase the number of surveys to make up for it. Secondly, this paper does neither consider the impact of employees on the projects' psychological ownership nor check the role of the trust levels among employees of stakeholders. However, these factors may offset partly the negative effects of the stakeholders on cooperative innovation. All these provide significant research directions for future studies [104].

\section{Appendix}

\section{Scale}

Psychological ownership:

(1) I think the problem of my stakeholder is my problem

(2) When someone praises my stakeholder, I feel honored

(3) I am very concerned about what other stakeholders of the project think about my stakeholder

(4) I have a strong sense of belonging to my stakeholder

(5) I am happy to stay with my stakeholder servicing for a long time

(6) For my career, my stakeholder has great significance

(7) I feel that I am part of this big family of my stakeholder

Territorial behaviors

External territorial behaviors:

(1) I am high alertness on other stakeholders' colleagues

(2) I draw a clear line with other stakeholders consciously or unconsciously

(3) I do not care about other stakeholders' matters

(4) If project owner's leader ask me to cooperate with other stakeholders, I am as perfunctory as possible

Internal territorial behaviors

(1) My stakeholder advocates the working mode of "let everyone mind his/her own business."

(2) Job contents and responsibilities for each member are clearly defined. Each does what his/her thinks is right and does not interfere with each other.

(3) My stakeholder's members are all very concerned about their own ideas and do not allow others to embezzle their ideas.

(4) My stakeholder's leaders emphasis on doing one's own work well than on cooperation with others.

Social loafing:

(1) While at work, I often go on desertions (daydreaming)

(2) At work, I pretend to be busy

(3) While at work, I fail to report trouble

(4) While at work, I need someone to help me to complete work properly 
(5) I put forth less effort on the job when others around are also able to do the work

(6) I give less effort than other members of the work group

Cooperative innovation performance:

(1) The proportion of stakeholders' joint participation in $\mathrm{R} \& \mathrm{D}$ work in the project total work is higher than that of ordinary construction projects implemented in the past

(2) Stakeholders joint participation in R\&D work can improve the satisfaction of the owner of the project

(3) In the process of stakeholders' joint participation in $R \& D$ work, our stakeholder members acquire new knowledge or new technology

(4) In the process of stakeholders' joint participation in R\&D work, all participating stakeholders of the project have acquired new knowledge or new technology

\section{Data Availability}

The data used to support the findings of the study can be obtained from the corresponding author upon request.

\section{Conflicts of Interest}

The authors declare that they have no conflicts of interest.

\section{Acknowledgments}

This work was supported by the Beijing Philosophy and Social Science Fund (Grant no. 17GLC057), the Basic Scientific Research Fund of Beijing Municipal Colleges (Grant no. X18174 and Grant no. ZF17046), and The Pyramid Talent Training Project of Beijing University of Civil Engineering and Architecture (Grant no. JDYC20200320).

\section{References}

[1] B. Flyvbjerg, "What you should know about megaprojects and why: an overview," Project Management Journal, vol. 45, no. 2, pp. 6-19, 2014.

[2] A. Van Marrewijk, S. R. Clegg, T. S. Pitsis, and M. Veenswijk, "Managing public-private megaprojects: p," International Journal of Project Management, vol. 26, no. 6, pp. 591-600, 2008.

[3] X. Li, J. Du, and H. Long, "Mechanism for green development behavior and performance of industrial enterprises (GDBP-IE) using partial least squares structural equation modeling (PLS-SEM)," International Journal of Environmental Research and Public Health, vol. 17, no. 22, p. 8450, 2020a.

[4] G. Brown, T. B. Lawrence, and S. L. Robinson, "Territoriality in organizations," Academy of Management Review, vol. 30, no. 3, pp. 577-594, 2005.

[5] J. Zhang, X. Fan, and J. Liu, "Exploration of organizational territoriality: from the perspective of individualism-collectivism cultural comparison," Foreign Economics \& Management, vol. 40, no. 6, pp. 73-85, 2018.
[6] S. Jiang, X. Zhang, Y. Cheng, D. Xu, P. Ordoñez De Pablos, and $\mathrm{X}$. Wang, "Dynamic impact of social network on knowledge contribution loafing in mobile collaboration: a hidden Markov model," Journal of Knowledge Management, vol. 23, no. 9, pp. 1901-1920, 2019.

[7] T.-C. Lin and C.-C. Huang, "Understanding social loafing in knowledge contribution from the perspectives of justice and trust," Expert Systems with Applications, vol. 36, no. 3, pp. 6156-6163, 2009.

[8] J. L. Pierce, T. Kostova, and K. T. Dirks, "Toward a theory of psychological ownership in organizations," Academy of Management Review, vol. 26, no. 2, pp. 298-310, 2001.

[9] J. L. Pierce, S. A. Rubenfeld, and S. Morgan, "Employee ownership: a conceptual model of process and effects," Academy of Management Review, vol. 16, no. 1, pp. 121-144, 1991.

[10] V. Capraro and M. Perc, "Mathematical foundations of moral preferences," Journal of The Royal Society Interface, vol. 18, no. 175, Article ID 20200880, 2021.

[11] G. Brown, "Claiming a corner at work: measuring employee territoriality in their workspaces," Journal of Environmental Psychology, vol. 29, no. 1, pp. 44-52, 2009.

[12] X. Fan, L. Lu, and J. Liu, "The effects of organizationally territorial climate on exploitative innovation from th interactionist perspective on organizational innovation A moderated mediation model," Journal of Industrial Engineering/Engineering Management, vol. 34, no. 2, pp. 40-49, 2020.

[13] S. Wu, Z. Sun, and Y. Quan, "Impact mechanism of zhongyong thinking on knowledge hiding and employees' creativity," Chinese Journal of Management, vol. 17, no. 4, pp. 527-535, 2020.

[14] Y. Wu, Y. Shao, and J. Yin, "The impact of strategic alliance ambidexterity on cooperativeinnovation performance: a moderated mediation model," Science \& Technology Progress and Policy, vol. 38, no. 2, pp. 1-10, 2020.

[15] F. Wei and Y. Ma, "Supervisor's territorial behavior and employee's knowledge hiding behavior: a moderated mediation model," Industrial Engineering \& Management, vol. 23, no. 4, pp. 179-185, 2018.

[16] B. Li and S. Shi, "A study of the relational model of knowledge territorial behaviors, knowledge sharing and individual innovation," Science \& Technology Progress and Policy, vol. 33, no. 8, pp. 140-145, 2016.

[17] Q. Liao, Y. Qin, and X. Zhang, "Relationship between psychological knowledge ownership and knowledge sharing: adjustment for organizational fairness," in Proceedings of the 8th International Conference on Innovation \& Management, Bangkok Thailand, October 2011.

[18] B. Li and S. Shi, "A study of the relational model of knowledge territorial Behaviors,Knowledge sharing and individual innovation," Science \& Technology Progress and Policy, vol. 33, no. 8, pp. 140-145, 2016b.

[19] L. Cheng, H. Yu, L. Zhang, and R. An, "How do organizational territorial behavior of scienctific and technological talents affects turnover intention: based on the moderating mediating model of psychological ownership and marriage," Science \& Technology Progress and Policy, vol. 36, no. 13, pp. 131-137, 2019.

[20] R. C. Liden, S. J. Wayne, R. A. Jaworski, and N. Bennett, "Social loafing: a field investigation," Journal of Management, vol. 30, no. 2, pp. 285-304, 2004.

[21] B. Meyer, C. C. Schermuly, and S. Kauffeld, "That's not my place: the interacting effects of faultlines, subgroup size, and 
social competence on social loafing behaviour in work groups," European Journal of Work \& Organizational Psychology, vol. 25, no. 1, pp. 31-49, 2016.

[22] S. J. Karau and K. D. Williams, "Social loafing: a meta-analytic review and theoretical integration," Journal of Personality and Social Psychology, vol. 65, no. 4, pp. 681-706, 1993.

[23] J. M. George, "Extrinsic and intrinsic origins of perceived social loafing in organizations," Academy of Management Journal, vol. 35, no. 1, pp. 191-202, 1992.

[24] P.-C. Lee, C.-M. Chen, and C.-H. Chou, "Decreasing tax collectors' perceived social loafing through collaborative behaviors of taxpayers," Journal of Public Administration Research and Theory, vol. 24, no. 4, pp. 1037-1063, 2014.

[25] D. O. Ozbey and A. G. Kapusuz, "Do the strategic innovative organizations reduce social loafing behaviors?" Independent Journal of Management \& Production, vol. 11, no. 6, pp. 2005-2019, 2020.

[26] L. Chidambaram and L. L. Tung, "Is out of sight, out of mind? an empirical study of social loafing in technologysupported groups," Information Systems Research, vol. 16, no. 2, pp. 149-168, 2005.

[27] K. H. Price, D. A. Harrison, and J. H. Gavin, "Withholding inputs in team contexts: member composition, interaction processes, evaluation structure, and social loafing," Journal of Applied Psychology, vol. 91, no. 6, pp. 1375-1384, 2006.

[28] G. Byun, S. Lee, S. J. Karau, and Y. Dai, "Sustaining collaborative effort in work teams: exchange ideology and employee social loafing," Sustainability, vol. 12, no. 15, p. 6241, 2020.

[29] R. C. Liden, S. J. Wayne, R. A. Jaworski, and N. Bennett, "Social loafing: a field investigation," Journal of Management, vol. 30, no. 2, pp. 285-304, 2016.

[30] H. Sun, L. Zhang, and J. Meng, "Alleviating knowledge contribution loafing among engineering designers by ethical leadership: the role of knowledge-based psychological ownership and emotion regulation strategies," Journal of Knowledge Management, vol. 24, no. 2, pp. 235-257, 2020.

[31] P.-C. Lee, C.-M. Chen, and C.-H. Chou, "Decreasing tax collectors' perceived social loafing through collaborative behaviors of taxpayers," Journal of Public Administration Research and Theory, vol. 24, no. 4, pp. 1037-1063, 2014b.

[32] D. Varshney, "Relationship between social loafing and the self-concept," Journal of Indian business research, vol. 11, no. 1, pp. 60-74, 2019.

[33] R. Høigaard, R. Säfvenbom, and F. E. Tønnessen, "The relationship between group cohesion, group norms, and perceived social loafing in soccer teams," Small Group Research, vol. 37, no. 3, pp. 217-232, 2016.

[34] V. Peñarroja, V. Orengo, and A. Zornoza, "Reducing perceived social loafing in virtual teams: the effect of team feedback with guided reflexivity," Journal of Applied Social Psychology, vol. 47, no. 8, pp. 424-435, 2017.

[35] O. A. Alnuaimi, L. P. Robert, and L. M. Maruping, "Team size, dispersion, and social loafing in technology-supported teams: a perspective on the theory of moral disengagement," Journal of Management Information Systems, vol. 27, no. 1, pp. 203-230, 2014.

[36] M. Arevalillo-Herráez, "Impact evaluation of reactive assessment strategies to address social loafing by promoting student cooperation and encouraging mutual support," Innovations in Education \& Teaching International, vol. 51, no. 5, pp. 523-532, 2014.
[37] S. Schindler and G. Reese, "Social loafing in the refugee crisis: information about existing initiatives decreases willingness to help," Societies, vol. 7, no. 2, p. 13, 2017.

[38] C.-C. Teng and Y.-P. Luo, "Effects of perceived social loafing, social interdependence, and group Affective tone on students' group learning performance," The Asia-Pacific Education Researcher, vol. 24, no. 1, pp. 259-269, 2015.

[39] R. B. Lount and S. L. Wilk, "Working harder or hardly working? posting performance eliminates social loafing and promotes social laboring in workgroups," Management Science, vol. 60, no. 5, pp. 1098-1106, 2014.

[40] T. Haugen, M. Reinboth, K. J. Hetlelid, D. M. Peters, and R. Høigaard, "Mental toughness moderates social loafing in cycle time-trial performance," Research Quarterly for Exercise \& Sport, vol. 87, no. 3, pp. 305-310, 2016.

[41] E. M. Stark, J. D. Shaw, and M. K. Duffy, "Preference for group work, winning orientation, and social loafing behavior in groups," Group \& Organization Management, vol. 32, no. 6, pp. 699-723, 2016.

[42] C. Chen, X. Martin, S. Roychowdhury, X. Wang, and M. T. Billett, "Clarity begins at home: internal information asymmetry and external communication quality," The Accounting Review, vol. 93, no. 1, pp. 71-101, 2018.

[43] R. B. Thompson and B. Thornton, "Gender and theory of mind in preschoolers' group effort: evidence for timing differences behind children's earliest social loafing," The Journal of Social Psychology, vol. 154, no. 6, pp. 475-479, 2014.

[44] H. E. Ülke and R. Bilgiç, "Investigating the role of the big five on the social loafing of information technology workers1," International Journal of Selection and Assessment, vol. 19, no. 3, pp. 301-312, 2011.

[45] K. K. Mihelič and B. Culiberg, "Reaping the fruits of another's labor: the role of moral meaningfulness, mindfulness, and motivation in social loafing," Journal of Business Ethics, vol. 160, no. 3, pp. 713-727, 2019.

[46] D. L. Smrt and S. J. Karau, "Protestant work ethic moderates social loafing," Group Dynamics: Theory, Research, and Practice, vol. 15, no. 3, pp. 267-274, 2011.

[47] Y. Chang, R.-J. Hou, K. Wang, A. P. Cui, and C.-B. Zhang, "Effects of intrinsic and extrinsic motivation on social loafing in online travel communities," Computers in Human Behavior, vol. 109, Article ID 106360, 2020.

[48] H. Hoon and T. M. L. Tan, "Organizational citizenship behavior and social loafing: the role of personality, motives, and contextual factors," Journal of Psychology, vol. 142, no. 1, pp. 89-108, 2008.

[49] Y. Akgunduz and G. Eryilmaz, "Does turnover intention mediate the effects of job insecurity and co-worker support on social loafing?" International Journal of Hospitality Management, vol. 68, pp. 41-49, 2018a.

[50] Z. Luo, H. Qu, and E. Marnburg, "Justice perceptions and drives of hotel employee social loafing behavior," International Journal of Hospitality Management, vol. 33, pp. 456464, 2013.

[51] S. J. Perry, N. M. Lorinkova, E. M. Hunter, A. Hubbard, and J. T. McMahon, "When does virtuality really "work"? examining the role of work-family and virtuality in social loafing," Journal of Management, vol. 42, no. 2, pp. 449-479, 2016.

[52] E. Xu, X. Huang, and S. L. Robinson, "When self-view is at stake: responses to ostracism through the lens of self-verification theory," Journal of Management, vol. 43, no. 7, pp. 2281-2302, 2017. 
[53] G. Wang, D. Liu, and X. Wang, "The role of bilateral specific investments on co-innovational performance in marketing channel," Nankai Business Review, vol. 14, no. 6, pp. 85-94, 2011a.

[54] V. Capraro and M. Perc, "Grand challenges in social physics: in pursuit of moral behavior," Frontiers in Physics, vol. 6, p. 107, 2018.

[55] L. Mieth, A. Buchner, and R. Bell, "Moral labels increase cooperation and costly punishment in a Prisoner's Dilemma game with punishment option," Scientific Reports, vol. 11, no. 1, pp. 1-13, 2021.

[56] P. R. Tomlinson, "Co-operative ties and innovation: some new evidence for UK manufacturing," Research Policy, vol. 39, no. 6, pp. 762-775, 2010.

[57] G. Chen and H. Zhang, "Relationship among organizational heterogeneity, interaction intensity and cooperative innovation performance," Forum on Science and Technology in China, vol. 2, pp. 28-35, 2020.

[58] A. Wu and X. Meng, "Inter-firm Behaviors, Social responsibility and Co-innovation performance," Science and Technology Management Research, vol. 21, pp. 141-147, 2015.

[59] X. Wang, J. Sun, L. Tian, W. Guo, and T. Gu, "Environmental dynamism and cooperative innovation: the moderating role of state ownership and institutional development," The Journal of Technology Transfer, vol. 46, 2020.

[60] G. De Jong and R. K. Woolthuis, "The institutional arrangements of innovation: antecedents and performance effects of trust in high-tech alliances," Industry \& Innovation, vol. 15, no. 1, pp. 45-67, 2008.

[61] J. Song, J. Chen, and Y. Sun, "The influence of core enterprise leadership style and inter-organizational trust on cooperative innovation performance," Forum on Science and Technology in China, vol. 11, pp. 73-78, 2013.

[62] Z.-J. Chen, X. Qin, and D. Vogel, "Is cooperation a panacea? The effect of cooperative response to task conflict on team performance," Systems Research and Behavioral Science, vol. 29, no. 2, pp. 163-178, 2012.

[63] L. Wang and H. Zhang, "Psychic distance, shared mental model and cooperative innovation performance of crossorganizational--the moderating effect of the value Co-creation," East China Economic Management, vol. 31, no. 11, pp. 143-150, 2017.

[64] J. B. Mabula, H. Dongping, and C. D. Chivundu-Ngulube, "SME manager'," Human Systems Management, vol. 39, no. 2, pp. 233-250, 2020.

[65] J. Yin and Y. Shao, "A research on how alliance portfolio management capability impacts on the focal firm's cooperative innovation performance," Chinese Journal of Management, vol. 15, no. 6, pp. 865-873, 2018.

[66] X. M. Xie, S. X. Zeng, and C. M. Tam, "How does cooperative innovation affect innovation performance? Evidence from Chinese firms," Technology Analysis \& Strategic Management, vol. 25, no. 8, pp. 939-956, 2013.

[67] X. Xie, S. Zeng, Z. Zang, and H. Zou, "Identifying the factors determining cooperative innovation effect in emerging economies," Chinese Management Studies, vol. 11, no. 3, pp. 366-386, 2017.

[68] A. Wu, "The mediating roles of governance mechanisms and knowledge transfer on the relationship between specific investments and cooperative innovation performance," Technology Analysis \& Strategic Management, vol. 28, no. 2, pp. 217-230, 2016a.
[69] A. Wu, Z. Wang, and S. Chen, "Impact of specific investments, governance mechanisms and behaviors on the performance of cooperative innovation projects," International Journal of Project Management, vol. 35, no. 3, pp. 504-515, 2017.

[70] R. Belderbos, M. Carree, and B. Lokshin, "Cooperative R\&D and firm performance," Research Policy, vol. 33, no. 10, pp. 1477-1492, 2004

[71] S. S. Levine and M. J. Prietula, "Open collaboration for innovation: principles and performance," Organization Science, vol. 25, no. 5, pp. 1414-1433, 2014.

[72] J. Song, "Innovation ecosystem: impact of interactive patterns, member location and member heterogeneity on cooperative innovation performance," Innovation, vol. 18, no. 1, pp. 13-29, 2016.

[73] G. Brown, C. Crossley, and S. L. Robinson, "Psychological ownership, territorial behavior, and being perceived as a team contributor: the critical role of trust in the work environment," Personnel Psychology, vol. 67, no. 2, pp. 463-485, 2014.

[74] H. Peng, "Why and when do people hide knowledge?" Journal of Knowledge Management, vol. 17, no. 3, pp. 398415, 2013.

[75] F. Bernstein, A. Gürhan Kök, and A. Meca, "Cooperation in assembly systems: the role of knowledge sharing networks," European Journal of Operational Research, vol. 240, no. 1, pp. 160-171, 2015.

[76] J. B. Avey, B. J. Avolio, C. D. Crossley, and F. Luthans, "Psychological ownership: theoretical extensions, measurement and relation to work outcomes," Journal of Organizational Behavior, vol. 30, no. 2, pp. 173-191, 2009.

[77] C. Liu, J. Liu, and L. Zhu, "Team territory behavior and knowledge sharing behavior: based on the perspective of identity theory," Human Resources Development of China, vol. 33, no. 21, pp. 61-70, 2016 a.

[78] P. de Faria, F. Lima, and R. Santos, "Cooperation in innovation activities: the importance of partners," Research Policy, vol. 39, no. 8, pp. 1082-1092, 2010.

[79] H. Jiao, J. Yang, J. Zhou, and J. Li, "Commercial partnerships and collaborative innovation in China: the moderating effect of technological uncertainty and dynamic capabilities," Journal of Knowledge Management, vol. 23, no. 7, pp. 1429-1454, 2019.

[80] J. Liu, X. Chen, and N. Xiao, "When collaboration requirements meet with "mountain - stronghold mentality": the impact of territorial behavior and task interdependence on team performance," Journal of South China Normal University (Social Science Edition), vol. 61, no. 5, pp. 99-109, 2016b.

[81] M. Černe, C. G. L. Nerstad, A. Dysvik, and M. Škerlavaj, "What goes around comes around: knowledge hiding, perceived motivational climate, and creativity," Academy of Management Journal, vol. 57, no. 1, pp. 172-192, 2014

[82] Y. Dai, Y. Hou, C. Wang, W. Zhuang, and Y. Liu, "TMX, social loafing, perceived accountability and OCB," Service Industries Journal, vol. 40, no. 5-6, pp. 394-414, 2020.

[83] X. Yu and C. Song, "The influence path analysis of ocb on innovation performance: based on the intermediary role of knowledge management," in Proceedings of the 2014 International Conference on Management Science \& Engineering 21th Annual Conference, Helsinki, Finland, August 2014.

[84] T. Braun, A. I. Ferreira, and J. Sydow, "Citizenship behavior and effectiveness in temporary organizations," International 
Journal of Project Management, vol. 31, no. 6, pp. 862-876, 2013.

[85] D. Zhang, P. Fonseca, L. Cuthbert, and S. Ketteridge, "An investigation of the team knowledge and team performance of the chinese engineering students in a senior technical module," in Proceedings of the 2014 IEEE Frontiers in Education Conference (FIE), Madrid, Spain, October 2014.

[86] M. Heene, S. Hilbert, C. Draxler, M. Ziegler, M. Bühner, and S. E. Maxwell, "Masking misfit in confirmatory factor Analysis by increasing unique variances: a cautionary note on the usefulness of cutoff values of fit indices," Psychological Methods, vol. 16, no. 3, pp. 319-336, 2011.

[87] R. C. Maccallum and J. T. Austin, "Applications of structural equation modeling in psychological research," Annual Review of Psychology, vol. 51, no. 1, pp. 201-226, 2000.

[88] K. Shaaban, I. Gharraie, E. Sacchi, and I. Kim, "Severity analysis of red-light-running-related crashes using structural equation modeling," Journal of Transportation Safety \& Security, vol. 13, no. 3, pp. 278-297, 2021.

[89] R. E. Zinbarg, W. Revelle, I. Yovel, and W. Li, "Cronbach", ”, Psychometrika, vol. 70, no. 1, pp. 123-133, 2005.

[90] Q. He, Z. Chen, and Y. Li, "The impact of megaprojects employee's psychological ownership on project performance in China: organizational ownership behavior as intermediary," Journal of Systems Management, vol. 26, no. 1, pp. 54-62, 2017.

[91] B. Flyvbjerg, "What you should know about megaprojects and why: an overview," Project Management Journal, vol. 45, no. 2, pp. 6-19, 2014.

[92] R. E. Kidwell Jr. and C. Robie, "Withholding effort in organizations: toward development and validation of a measure," Journal of Business and Psychology, vol. 17, no. 4, pp. 537-561, 2003.

[93] T. Sainati, N. Brookes, and G. Locatelli, "Special purpose entities in megaprojects: empty boxes or real companies?" Project Management Journal, vol. 48, no. 2, pp. 55-73, 2017.

[94] M. Irfan, Z.-Y. Zhao, A. Rehman, I. Ozturk, and H. Li, "Consumers'," Environmental Science and Pollution Research, vol. 28, no. 1, pp. 432-445, 2020.

[95] J. E. M. Steenkamp and H. Baumgartner, "On the use of structural equation models for marketing modeling," International Journal of Research in Marketing, vol. 17, no. 2, pp. 195-202, 2000.

[96] Y. Li, C. Chang, and B. Li, "Diversified spatio - temporal evolution of innovative collaboration meta - networks in megaprojects," Science Research Management, vol. 41, no. 10, pp. 98-104, 2020.

[97] A. Najmi, K. Kanapathy, and A. A. Aziz, "Understanding consumer participation in managing ICT waste: findings from two-staged structural equation modeling-artificial neural network approach," Environmental Science and Pollution Research, vol. 28, no. 12, pp. 14782-14796, 2020.

[98] B. T. Hazen, R. E. Overstreet, and C. A. Boone, "Suggested reporting guidelines for structural equation modeling in supply chain management research," International Journal of Logistics Management, 2015.

[99] B. Xiong, M. Skitmore, and B. Xia, "A critical review of structural equation modeling applications in construction research," Automation in Construction, vol. 49, pp. 59-70, 2015.

[100] W. Reinartz, M. Haenlein, and J. Henseler, "An empirical comparison of the efficacy of covariance-based and variancebased SEM," International Journal of Research in Marketing, vol. 26, no. 4, pp. 332-344, 2009.
[101] Y.-H. Fang, "Coping with fear and guilt using mobile social networking applications: knowledge hiding, loafing, and sharing," Telematics and Informatics, vol. 34, no. 5, pp. 779-797, 2017.

[102] W. Huo, Z. Cai, J. Luo, C. Men, and R. Jia, "Antecedents and intervention mechanisms: a multi-level study of R\&D team's knowledge hiding behavior," Journal of Knowledge Management, vol. 20, no. 5, pp. 880-897, 2016.

[103] M. C. Schippers, "Social loafing tendencies and team performance: the compensating effect of agreeableness and conscientiousness," The Academy of Management Learning and Education, vol. 13, no. 1, pp. 62-81, 2014.

[104] M. N. Karimi and N. Fallah, "Academic burnout, shame, intrinsic motivation and teacher affective support among Iranian EFL learners: a structural equation modeling approach," Current Psychology, vol. 40, no. 4, pp. 2026-2037, 2019. 